Esta obra forma parte del acervo de la Biblioteca Jurídica Virtual del Instituto de Investigaciones Jurídicas de la UNAM www.juridicas.unam.mx

\title{
LAS ELECCIONES EN AMÉRICA LATINA (2013-2014)
}

ELECTIONS IN LATIN AMERICA (2013-2014)

\section{Flavia FreidenberG ${ }^{1}$}

\section{Sumario:}

I. Introduccción

II. El contexto en el que se celebraron las elecciones

III. Principales tendencias de los resultados electorales en perspectiva comparada

IV. La maratón electoral en perspectiva comparada: lo que hemos aprendido y lo que aún queda por aprender

V. Fuentes consultadas

RESUMEN: América Latina ha experimentado un intenso calendario electoral entre 2013 y 2014. El objetivo de este artículo es identificar las principales tendencias que surgen de estos procesos en doce países de América Latina. La evidencia comparada da cuenta de al menos seis hallazgos: a) las elecciones se han institucionalizado como parte del "único juego posible en la ciudad" y continúan siendo mecanismos claves para dirimir quién detenta el poder; b) existe un alto nivel de participación ciudadana en la mayoría de los países de la región; c) las elecciones tienden a ser reñidas, con resultados estrechos, altos niveles de incertidumbre, en escenarios hipercompetitivos y con una fuerte polarización ideológica; d) los candidatos que detentan el poder suelen ser reelegidos; e) la fragmentación de los sistemas de partidos muy extremos se ha reducido, y f) se han reforzado las organizaciones de partidos como articuladoras de la competencia política en el marco de un contexto de fuerte descreimiento ciudadano con la política y los partidos.

Palabras clave: Elecciones, partidos políticos, sistema de partidos, América Latina.

\section{INTRODUCCIÓN ${ }^{2}$}

\footnotetext{
${ }^{1}$ Investigadora del Instituto de Investigaciones Jurídicas de la UNAM.

2 El estudio se desarrolló en el marco de una estancia de investigación realizada en el Centro de Estudios de Opinión Pública de la Universidad Estadual de Campinas (CESOP-UNICAMP), financiada por FAPESP,
} 
Esta obra forma parte del acervo de la Biblioteca Jurídica Virtual del Instituto de Investigaciones Jurídicas de la UNAM www.juridicas.unam.mx

En la actualidad, los países de América Latina son mucho más democráticos que hace cuatro décadas. Desde el proceso de redemocratización de la tercera ola, que se inició a fines de la década de 1970, la mayoría de los países de la región han celebrado elecciones competitivas, libres y justas, en el marco del respeto de los derechos políticos y las libertades cívicas. En este sentido, las últimas décadas han sido un periodo democrático sin precedentes en la región, tanto en extensión temporal como en la dimensión espacial de dichos procesos políticos.

Durante el 2013-2014, el continente americano ha vivido un intenso calendario electoral, ya que doce países han celebrado elecciones. La experiencia de ciclos de elecciones en un mismo año no es novedad. El ciclo (2013-2014) es el cuarto de este tipo desde el retorno a la democracia en esa tercera ola. En otras tres oportunidades (1989, 1994, 2005-2006), también un número significativo de países tuvieron elecciones presidenciales, legislativas y/o municipales en el mismo momento, lo que da cuenta de ciclos de elecciones que ponen en evidencia la salud de las democracias latinoamericanas. Dado que las elecciones son el corazón de la democracia representativa, el hecho de que se celebren elecciones libres, justas y competitivas facilita que la ciudadanía viva en un sistema democrático. ${ }^{3}$

Los procesos electorales han ido rutinizando la "poliarquía" ${ }^{4}$ han generado un extensivo consenso en torno a que las elecciones funcionan como el "único juego posible en la ciudad" ${ }^{5}$ y como el mecanismo más idóneo para la distribución del poder entre los diversos actores políticos. La mayoría de los países han configurado sistemas de partidos con dinámicas de competencia estables, que han permeado una serie de prácticas formales e informales; han ido incorporando a sectores que se sentían excluidos, ampliando los márgenes representativos de los sistemas políticos y han ido reconfigurando los aprendizajes políticos que van asumiendo (y exigiendo) el respeto de los valores y las prácticas de la democracia pluralista. ${ }^{6}$ Esto ha ocurrido a

entre el 21 de julio y el 21 de agosto de 2014. Una versión previa de este trabajo fue presentado en el IX Congreso de la Asociación Brasilera de Ciencia Política, celebrado en Brasilia, del 4 al 8 de agosto de 2014.

${ }^{3}$ Schattschneider, Elmer E., Party Government, Nueva York, Holt, Rinehart and Winston, 1942.

4 Dahl, Robert, La poliarquía, Madrid, Tecnos, 1971.

${ }^{5}$ Linz, Juan J., La quiebra de las democracias, Madrid, Alianza Editorial, 1987.

${ }^{6}$ Freidenberg, Flavia (ed.), Los sistemas de partidos de América Latina, 1978-2015, México, Instituto Nacional Electoral, Tribunal Electoral del Poder Judicial de la Federación e Instituto de Iberoamérica, Universidad de Salamanca, en prensa, 2005. 
Esta obra forma parte del acervo de la Biblioteca Jurídica Virtual del Instituto de Investigaciones Jurídicas de la UNAM www.juridicas.unam.mx

pesar de las dificultades de algunos sistemas políticos para garantizar el ejercicio del monopolio legítimo de la coacción física en todo el territorio como en: México, Brasil, Honduras, Argentina o El Salvador y de la presencia de grupos paraestatales paramilitares, mafias o crimen organizado- y caudillos locales que permean y limitan esas instituciones poliárquicas y suponen la vigencia de regímenes híbridos ${ }^{7} 0$ de autoritarismos subnacionales. ${ }^{8}$ Si bien, existen problemas de "integridad" en las condiciones de la competencia y en la organización de los procesos electorales ${ }^{9}$ (Informes de las Misiones de Observación Electoral de la Organización de los Estados Americanos) y obstáculos en la democratización de las sociedades, la región se encuentra en el periodo de mayor competencia electoral de su historia.

El objetivo de este trabajo es identificar las principales características o patrones que surgen de los procesos electorales que se han realizado en doce países de América Latina entre enero de 2013 y diciembre de 2014 (Tabla Núm. 1). En este periodo se han celebrado elecciones en cuatro países del cono sur (Paraguay, Chile, Uruguay, Brasil), en cuatro países andinos (Bolivia, Colombia, Ecuador, Venezuela), tres de América Central (Honduras, Costa Rica, El Salvador) y en Panamá. Además, se llevaron a cabo diez elecciones legislativas de las cuales ocho fueron elecciones concurrentes a las presidenciales (Honduras, Uruguay, Chile, Ecuador, Bolivia, Paraguay, Costa Rica y Brasil); una(s) parcialmente concurrente(s) en Colombia —dos meses antes de las presidenciales- y otra(s) separada(s) por dos años de la presidencial (Argentina, donde se elige la mitad del Congreso). ${ }^{10}$

Esta investigación identifica al menos seis tendencias del análisis de las elecciones realizadas durante el maratón electoral de 2013-2014 como: a) la rutinización y consolidación de las elecciones como los mecanismos para dirimir quién detenta el poder; b) un alto nivel de participación ciudadana en la mayoría de los países (destacando los niveles de más del $90 \%$ de Bolivia); c) resultados estrechos con altos niveles de incertidumbre, en escenarios hipercompetitivos y con una fuerte

\footnotetext{
7 Levitsky, Steven y Way, Lucas, “Elecciones sin democracia: el surgimiento de los regímenes autoritarios competitivos", Estudios Políticos, Colombia, vol. 24, enero-junio, 2004, pp.159-176.

${ }^{8}$ Gervasoni, Carlos, "Democracia, autoritarismo e hibridez en las provincias argentinas: la medición y causa de los regímenes subnacionales", Journal of Democracy en Español, vol. 3, 2011, pp. 75-93.

${ }^{9}$ Norris, Pippa, Why Electoral Integrity Matters. Nueva York, Cambridge University Press, 2014.

${ }^{10}$ También se realizaron seis elecciones municipales, algunas concurrentes (Bolivia, Panamá, Honduras y Venezuela) y otras separadas de las presidenciales y legislativas (Perú y Ecuador).
} 
Esta obra forma parte del acervo de la Biblioteca Jurídica Virtual del Instituto de Investigaciones Jurídicas de la UNAM www.juridicas.unam.mx

DOI: http://dx.doi.org/10.22201/iij_.24487910e_2015.7.10092

polarización ideológica (Brasil, Venezuela, Costa Rica, Colombia o El Salvador); d) gobernantes reelectos (Brasil, Colombia, Bolivia o Ecuador) o partidos reelectos a nivel presidencial (El Salvador y Venezuela); e) la reducción de la fragmentación de los sistemas de partidos que tradicionalmente habían sido muy fragmentados (Ecuador, Brasil o Bolivia), y f) el reforzamiento de organizaciones de partidos como articuladoras de la competencia política en el marco de un contexto de fuerte descreimiento ciudadano de la política y de los propios partidos -como ocurrió con el PT en Brasil, el Frente Amplio en Uruguay, la Concertación en Chile, el MAS boliviano o los partidos paraguayos, entre otros-.

El texto tiene cuatro partes. Primero, se analiza el contexto en el que se realizaron las elecciones en términos de institucionalización democrática. Segundo, se identifican las características de las elecciones a partir de sus principales propiedades (incertidumbre, alternancia) así como las características de la oferta partidista y la dinámica del sistema de partidos: competitividad, fragmentación, polarización ideológica, gobierno divididos, papel de las organizaciones de partidos, etcétera). Finalmente, reflexiona sobre el modo en que estas elecciones engarzan en el marco de las cuatro décadas de proceso de redemocratización que vive la región.

Tabla Núm. 1

Calendario electoral en América Latina (2013-2014)

\begin{tabular}{|c|c|c|}
\hline Fecha & País & Tipo de elección \\
\hline $\begin{array}{l}26 \text { de octubre de } 2014 \\
30 \text { de noviembre de } 2014\end{array}$ & Uruguay & $\begin{array}{l}\text { Presidencial (1 ra vuelta) } \\
\text { Presidencial (2da vuelta) }\end{array}$ \\
\hline 12 de Octubre de 2014 & Bolivia & Presidencial, legislativa y municipal \\
\hline $\begin{array}{l}5 \text { de octubre de } 2014 \\
2 \text { de noviembre de } 2014\end{array}$ & Brasil & $\begin{array}{l}\text { Presidencial (1ra vuelta), legislativa } \\
\text { presidencial (2da vuelta) }\end{array}$ \\
\hline 5 de octubre de 2014 & Perú & Municipales \\
\hline $\begin{array}{l}9 \text { de marzo de } 2014 \\
25 \text { de mayo de } 2014 \\
15 \text { de junio de } 2014\end{array}$ & Colombia & $\begin{array}{l}\text { Legislativas } \\
\text { Presidencial (1ra vuelta) } \\
\text { Presidencial ( } 2 \text { da vuelta) }\end{array}$ \\
\hline 4 de mayo de 2014 & Panamá & Presidencial, legislativa y municipal \\
\hline $\begin{array}{l}2 \text { de febrero de } 2014 \\
6 \text { de abril del } 2014\end{array}$ & Costa Rica & $\begin{array}{l}\text { Presidencial (1ra vuelta), legislativa } \\
\text { presidencial (2da vuelta) }\end{array}$ \\
\hline
\end{tabular}


Esta obra forma parte del acervo de la Biblioteca Jurídica Virtual del Instituto de Investigaciones Jurídicas de la UNAM www.juridicas.unam.mx

Dol: http://dx_doi.org/10.22201/iij.24487910e_2015.7.10092

\begin{tabular}{|l|l|l|}
\hline $\begin{array}{l}23 \text { de febrero de } 2014 \\
\text { 17 de febrero de } 2013\end{array}$ & Ecuador & $\begin{array}{l}\text { Punicipales } \\
\text { Presidencial (1ra vuelta), legislativa } \\
\text { Presidencial (2da vuelta) }\end{array}$ \\
\hline $\begin{array}{l}2 \text { de febrero de } 2014 \\
9 \text { del marzo de } 2014\end{array}$ & El Salvador & $\begin{array}{l}\text { Presidencial (1ra vuelta) } \\
\text { Presidencial (2da vuelta) }\end{array}$ \\
\hline 17 de noviembre de 2013 & Chile diciembre de 2013 & Presidencial (1ra vuelta), legislativa \\
\hline 24 de noviembre de 2013 & Honduras & Presidencial, legislativa y municipal \\
\hline 27 de octubre de 2013 & Argentina & Legislativa \\
\hline 21 de abril de 2013 & Paraguay & Presidencial y legislativa \\
\hline 14 de abril de 2013 & Venezuela & Presidencial y municipal \\
\hline
\end{tabular}

Fuente: elaboración propia.

\section{EL CONTEXTO EN EL QUE SE CELEBRARON LAS ELECCIONES}

Las elecciones pueden ser descritas como un "juego de barajas", en el que compiten una serie de individuos y/o grupos, con sus ideas, propuestas y recursos, donde algunos ganan y otros pierden, en un contexto de imparcialidad y equilibro de fuerzas en el escenario de la contienda. La democracia supone que los que pierden la contienda aceptan los resultados de ese juego, incluso cuando no les favorecen los resultados. Por dicha razón, ser demócrata implica precisamente aprender a perder elecciones.

Los doce países de la región que celebraron elecciones en América Latina renovaron su compromiso democrático al realizar procesos acordes a los términos constitucionales, cumpliendo los plazos estipulados por las normas, rutinizando el funcionamiento del sistema democrático y dieron oportunidad para el ejercicio de la alternancia en un escenario donde los perdedores aceptaron los resultados. En ninguno de los países analizados hubo denuncias de fraude sistemático o de irregularidades tan significativas que pusieran en duda los resultados de la elección (Informes MOE-OEA), ${ }^{11}$ aún cuando en algunos (como en Ecuador) los mismos informes de las MOE-OEA indicaron que las condiciones de la competencia no

\footnotetext{
${ }^{11}$ Los Informes de las Misiones de Observación Electoral están disponibles en la página oficial de la Organización de los Estados Americanos, http://www.oas.org/es/sap/deco/moe.asp
} 
Esta obra forma parte del acervo de la Biblioteca Jurídica Virtual del Instituto de Investigaciones Jurídicas de la UNAM www.juridicas.unam.mx

DOI: http://dx.doi.org/10.22201/iij_.24487910e_2015.7.10092

estaban equilibradas y que algunas "canchas estaban inclinadas", ya que no todos los actores contaban con los mismos recursos ni las mismas condiciones para una competencia equitativa.

Estas condiciones diferenciadas están relacionadas con el hecho de que en los países que tuvieron elecciones dentro del maratón 2013-2014 existían contextos con diferentes niveles de desarrollo democrático (IDD-Lat. 2013) (Gráfico Núm. 1), al observar el rendimiento de las instituciones, la vigencia del Estado de derecho, el ejercicio de poder efectivo para gobernar, la calidad institucional, el nivel de eficacia política o el modo en que se respetan las libertades civiles y los derechos políticos. ${ }^{12}$

Las elecciones en Uruguay, Chile y Costa Rica se realizaron en el marco de un alto desarrollo democrático; lo que significa que éstos presentan variaciones positivas en todas las dimensiones del índice (respeto de las libertades civiles y derechos políticos; calidad institucional y vigencia del Estado de derecho, y satisfacción con el rendimiento de las instituciones democráticas).

Las elecciones en Panamá, Argentina (legislativa), Perú (regionales) y Brasil se realizaron en un contexto de niveles de desarrollo democrático medio mientras que en El Salvador, Colombia, Bolivia, Ecuador, Honduras y Paraguay las elecciones se dieron en contextos con bajo nivel de desarrollo democrático, ${ }^{13}$ con problemas de integridad electoral y de incapacidad estatal para garantizar la seguridad de la ciudadanía.

Gráfico Núm. 1

Índice de desarrollo democrático en América Latina (2013)

\footnotetext{
12 Una revisión de la metodología empleada para el cálculo de este índice se puede encontrar en http://WWw.idd-lat.org/2014/cuestiones_metodologicas/12/index.htm/

${ }^{13}$ Los datos de este índice muestran tres grupos de países: los de alto desarrollo democrático (Uruguay, Chile y Costa Rica); Ios de desarrollo medio (Perú, Argentina, México, Panamá y Brasil); bajo desarrollo (EI Salvador, Colombia, Bolivia, Nicaragua, Ecuador, Honduras y República Dominicana), y desarrollo mínimo (Paraguay, Guatemala y Venezuela). Una revisión de la metodología empleada para el cálculo de este índice se puede encontrar en http://www.idd-lat.org/2014/cuestiones_metodologicas/12/index.htm/
} 
Esta obra forma parte del acervo de la Biblioteca Jurídica Virtual del Instituto de Investigaciones Jurídicas de la UNAM www.juridicas.unam.mx

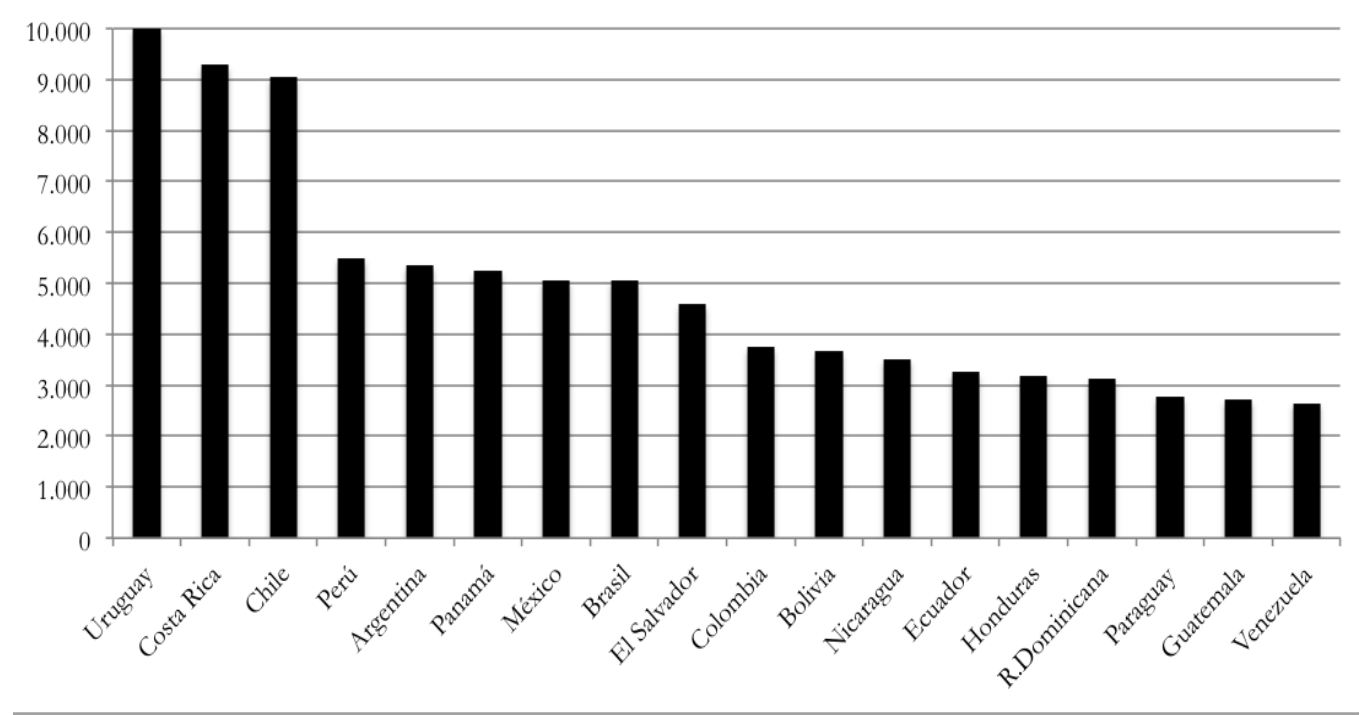

Fuente: IDD-Lat. (2013).

\section{PRINCIPALES TENDENCIAS DE LOS RESULTADOS ELECTORALES EN PERSPECTIVA COMPARADA}

\section{La rutinización de las reglas de juego}

En los sistemas políticos latinoamericanos, el presidente se elige de manera directa, aunque han existido periodos en los que algunos países han empleado la elección indirecta a través de Colegios Electorales como en Argentina (hasta 1994) o Brasil (hasta 1989). En donde se elige al presidente de manera directa se suelen emplear dos fórmulas electorales diferentes: la de mayoría simple (en una sola vuelta) ${ }^{14} \mathrm{o} \mathrm{la}$ de mayoría a dos vueltas (balotaje), cuando el candidato requiere un determinado nivel de votación para ganar la elección en la primera vuelta y si esto no se logra, se va a una segunda vuelta entre los dos candidatos más votados.

A partir de la década de 1970, el sistema de doble vuelta ha sido la reforma dominante en la manera de elegir al Poder Ejecutivo en América Latina (Freidenberg y Došek 2014). En Ecuador (1978), Perú (1979), El Salvador (1983), Guatemala (1985), Haití (1989), Brasil (1988), Chile (1989), Colombia (1991), Argentina (1994), Nicaragua (1995), ${ }^{15}$ República Dominicana (1996) o Uruguay (1996) se introdujo este sistema de elección, con diferencias en las modalidades necesarias para pasar a la segunda vuelta de un país a otro y si se elige directamente por la ciudadanía o, como en

\footnotetext{
${ }^{14}$ Bajo la primera fórmula, resulta ganador el candidato que obtenga la votación más elevada entre los participantes en una única vuelta como en Panamá, Paraguay, Honduras, México y Venezuela.

${ }^{15}$ Aunque se ha eliminado en 2013.
} 
Esta obra forma parte del acervo de la Biblioteca Jurídica Virtual del Instituto de Investigaciones Jurídicas de la UNAM www.juridicas.unam.mx

Bolivia desde 1967 donde la elección en segunda vuelta la realiza el Congreso. ${ }^{16}$

Para el ciclo 2013-2014, de los doce países que celebraron elecciones presidenciales, ocho podían haber activado la doble vuelta, ya que así lo establecían las normas constitucionales. ${ }^{17}$ De esos ocho países, seis usaban la fórmula de mayoría absoluta (50\% más uno de los votos), Uno estableció márgenes reducidos para ganar en primera vuelta (40\% devotos en Costa Rica) y otros dos adoptaron la mayoría absoluta o, en su caso, se presentó una combinación especial entre porcentaje y puntos porcentuales (Ecuador y Bolivia disponen la mayoría absoluta y/o el 40\%, con diez puntos de diferencia) (Tabla Núm. 2).

Tabla Núm. 2

Sistema de elección presidencial en las elecciones de 2013-2014

\begin{tabular}{|c|c|c|c|}
\hline País & $\begin{array}{l}\text { Sistema } \\
\text { presidencial }\end{array}$ & $\begin{array}{l}\% \text { necesario en la } \\
\text { primera vuelta para } \\
\text { no pasar a la } \\
\text { segunda }\end{array}$ & $\begin{array}{l}\text { Reelección } \\
\text { presidencial (año } \\
\text { de aprobación) }\end{array}$ \\
\hline Bolivia & $\begin{array}{l}\text { Doble vuelta con } \\
\text { mayoría }\end{array}$ & $\begin{array}{l}50 \% \text { o } 40 \% \text {, con } 10 \\
\text { puntos de diferencia }\end{array}$ & Inmediata (2009) \\
\hline Brasil & $\begin{array}{l}\text { Doble vuelta con } \\
\text { mayoría }\end{array}$ & $50 \%$ & $\begin{array}{l}\text { Si, inmediata por } \\
\text { un periodo (1997) }\end{array}$ \\
\hline Chile & $\begin{array}{l}\text { Doble vuelta con } \\
\text { mayoría }\end{array}$ & $50 \%$ & $\begin{array}{l}\text { Si, luego de un } \\
\text { periodo (1990) }\end{array}$ \\
\hline Colombia & $\begin{array}{l}\text { Doble vuelta con } \\
\text { mayoría }\end{array}$ & $50 \%$ & $\begin{array}{l}\text { Si, luego de un } \\
\text { periodo (2005) }\end{array}$ \\
\hline Costa Rica & $\begin{array}{l}\text { Doble vuelta con umbral } \\
\text { reducido }\end{array}$ & $40 \%$ & $\begin{array}{l}\text { Si, luego de dos } \\
\text { periodos (2003) }\end{array}$ \\
\hline Ecuador & $\begin{array}{l}\text { Doble vuelta con umbral } \\
\text { reducido }\end{array}$ & $\begin{array}{l}50 \% \text { o } 40 \text { más } 10 \\
\text { puntos de diferencia }\end{array}$ & $\begin{array}{ll}\text { Si, inmediata por } \\
\text { una única vez } \\
(2008) & \end{array}$ \\
\hline El Salvador & vuelta & $50 \%$ & Si, luego de dos \\
\hline
\end{tabular}

\footnotetext{
${ }^{16}$ En Costa Rica el sistema de doble vuelta se emplea desde 1949.

17 Freidenberg, Flavia y Došek, Tomás, “Las reformas electorales y la fortaleza institucional en América Latina", Trabajo presentado para su discusión en el II Congreso Internacional de Estudios Electorales, organizado por el Jurado Nacional de Elecciones, Lima, del 27 al 29 de noviembre de 2014.
} 
Esta obra forma parte del acervo de la Biblioteca Jurídica Virtual del Instituto de Investigaciones Jurídicas de la UNAM www.juridicas.unam.mx

DOI: http://dx.doi.org/10.22201/iij.24487910e_2015.7.10092

\begin{tabular}{|l|l|l|l|}
\hline & mayoría & & periodos (2014) \\
\hline Honduras & Mayoría relativa & - & No \\
\hline Panamá & Mayoría relativa & - & $\begin{array}{l}\text { Si, luego de dos } \\
\text { periodos } \\
\text { intermedios (2002) }\end{array}$ \\
\hline Uruguay & $\begin{array}{l}\text { Doble vuelta con } \\
\text { mayoría }\end{array}$ & $50 \%$ & No \\
\hline Venezuela & Mayoría relativa & - & $\begin{array}{l}\text { Si, luego de un } \\
\text { periodo (1996) }\end{array}$ \\
\hline
\end{tabular}

Fuente: elaboración propia a partir de la normativa vigente y Freidenberg

$$
\text { y Došek (2014). }
$$

Aun cuando el debate sobre las bondades de este sistema no está acabado, ${ }^{18}$ de los doce procesos electorales presidenciales que llevaron a cabo la doble vuelta en seis países se puso en práctica (Chile, Uruguay, Brasil, Costa Rica, El Salvador, Colombia), mientras que en dos se definió en la primera ronda (Ecuador y Bolivia), con resultados que superaron los 50 puntos porcentuales el apoyo al candidato del partido en el gobierno (incumbent). Los otros cuatro países que tuvieron elecciones durante este periodo y que no cuentan con el sistema de doble vuelta en su legislación son Honduras: Panamá, Paraguay y Venezuela.

De los casos donde fue necesario ir a una segunda vuelta (Chile, Costa Rica, El Salvador, Uruguay, Brasil y Colombia), el resultado se revirtió sólo en Colombia mientras que en el resto de los países el ganador de la primera vuelta confirmó su triunfo en el ballotage (Costa Rica, Brasil, Uruguay, El Salvador, Uruguay, Brasil). En Colombia, el ganador de la primera vuelta fue el candidato de la corriente uribista,

18 Sus defensores destacan que fortalece la legitimidad electoral del presidente porque garantiza la superación de un umbral electoral mínimo, permite que sea el electorado el que dirima la contienda en caso de que ningún candidato supere ese umbral en la primera vuelta y favorece la gobernabilidad al garantizar un presidente con amplio respaldo popular. Entre las críticas se argumenta que se incrementa la fragmentación partidista; no garantiza la gobernabilidad democrática, disminuye la posibilidad de que se celebren alianzas y genera menos incentivos para el voto estratégico, véase Pérez-Liñán, Aníbal, “Los efectos del ballotage en los sistemas electorales y de partidos en América Latina", trabajo presentado para el Segundo Seminario Iberoamericano sobre Partidos Políticos, Cartagena de Indias, septiembre de 2006; Zovatto, Daniel, “Elecciones y democracia en América Latina. Balance electoral latinoamericano noviembre 2005-diciembre 2006", presentada en el Seminario de Balance Electoral de América Latina, organizado en el Centro de Estudios Constitucionales, Madrid, 13 de diciembre de 2006. 
Esta obra forma parte del acervo de la Biblioteca Jurídica Virtual del Instituto de Investigaciones Jurídicas de la UNAM www.juridicas.unam.mx

DOI: http://dx.doi.org/10.22201/iij.24487910e_2015.7.10092

Óscar Iván Zuluaga (Centro Democrático) con el 29.26\% de los votos; el segundo lugar fue Juan Manuel Santos (Unidad Nacional), quien recibió 25.69\% de la votación. Estos resultados se revirtieron en la segunda vuelta electoral, dando por ganador al incumbent y facilitando la reelección de Santos. Este último obtuvo $50.95 \%$ de los votos, mientras que Zuluaga se quedó con sólo 45\%. Cabe señalar que esta situación ya había ocurrido en la elección de Andrés Pastrana en 1998 frente a Horacio Serpa.

En Costa Rica, Luis Guillermo Solís, del desafiante Partido Acción Ciudadana (PAC), revalidó su triunfo de una reñida primera vuelta (2 de febrero de 2014). En este caso, el contexto fue muy peculiar, ya que el candidato oficialista y favorito de las encuestas tres meses antes de la elección, Johnny Araya del gobernante Partido Liberación Nacional (PLN), amagó con renunciar en medio del proceso electoral antes de la segunda vuelta. A pesar de sus intenciones, las reglas electorales no permitieron el abandono de la candidatura entre la primera y la segunda vuelta, lo que hizo que apareciera su nombre en la papeleta.

Tabla Núm. 3

Elecciones presidenciales, resolución de las elecciones y doble vuelta en América Latina

\begin{tabular}{|l|l|l|l|}
\hline País & Elecciones & \multicolumn{3}{|l|}{$\begin{array}{l}\text { Resolución de las elecciones } \\
\text { (sólo en las que existía la posibilidad de } \\
\text { la doble vuelta) }\end{array}$} \\
\hline & $\begin{array}{l}\text { Primera vuelta } \\
\text { (año) }\end{array}$ & $\begin{array}{l}\text { Segunda } \\
\text { vuelta } \\
\text { (año) }\end{array}$ \\
\hline Argentina & $83,89,95,99,03,07,11$ & $95,99,03,07,11$ & \\
\hline Bolivia & $\begin{array}{l}80,82,85,89,93,97,02,05,09, \\
14\end{array}$ & $80,05,09,14$ & $85,89,93,97,02$ \\
\hline Brasil & $89,94,98,02,06,10,14$ & $94,98,10$ & $89,02,06,14$ \\
\hline Chile & $89,93,99,05,09,13$ & 89,93 & $99,05,09,13$ \\
\hline Colombia & $\begin{array}{l}78,82,86,90,94,98,02,06,10, \\
14\end{array}$ & 02,06 & $94,98,10,14$ \\
\hline Ecuador & $\begin{array}{l}79,84,88,91,96,98,02,06,09, \\
13\end{array}$ & 09,13 & $\begin{array}{l}79,84,88,91,96 \\
98,02,06\end{array}$ \\
\hline
\end{tabular}


Esta obra forma parte del acervo de la Biblioteca Jurídica Virtual del Instituto de Investigaciones Jurídicas de la UNAM www.juridicas.unam.mx

DOl: http://dx.doi.org/10.22201/iij.24487910e.2015.7.10092

\begin{tabular}{|c|c|c|c|}
\hline Costa Rica & $\begin{array}{l}49,53,58,62,66,74,78,82,86 \\
90,94,98,02,06,10,14\end{array}$ & $\begin{array}{l}49,53,58,62,6674,78 \\
82,86,90,94,98,06,10\end{array}$ & 02,14 \\
\hline El Salvador & $94,99,04,09,14$ & $99,04,09$ & 94,14 \\
\hline Guatemala & $85,90,95,99,07,11$ & 07 & $\begin{array}{l}85,90,95,99,08 \\
12\end{array}$ \\
\hline Honduras & $80,85,89,93,97,01,05,09,13$ & - & \\
\hline México & $94,00,06,12$ & - & \\
\hline Nicaragua & $90,96,01,06,11$ & $90,96,06,11$ & 01 \\
\hline Panamá & $89,94,99,04,09,14$ & - & \\
\hline Paraguay & $89,93,98,08,13$ & - & \\
\hline Perú & $80,85,90,95,00,01,06,11$ & $80,85,95,11$ & $90,00,01,06$ \\
\hline Dominicana & $\begin{array}{l}78,82,86,90,94,96,00,04,08 \\
12\end{array}$ & $00,04,08,12$ & 96 \\
\hline Uruguay & $85,89,94,99,04,09,14$ & 04,09 & $99,10,14$ \\
\hline Venezuela & $\begin{array}{l}73,78,83,88,93,98,00,06,12 \\
13\end{array}$ & - & \\
\hline
\end{tabular}

Fuente: resultados electorales oficiales.

\section{Resultados estrechos, altos niveles de incertidumbre y escenarios}

\section{hipercompetitivos}

Las elecciones presidenciales de Brasil, Venezuela, Colombia, Costa Rica y El Salvador fueron de infarto. El nivel de incertidumbre de los resultados no tuvo precedentes en estos países. Los márgenes de victoria en Venezuela, Costa Rica (primera vuelta) y en El Salvador (segunda vuelta) fueron cercanos a un punto porcentual. En el primer caso la diferencia de la primera vuelta fue de $1.36 \%$ (equivalente a 25.045 votos) y, en el segundo fue de $0.22 \%$ (equivalente a 6.364 votos) en la segunda vuelta. En Colombia, la diferencia de votos entre los candidatos más votados fue menor a los seis puntos porcentuales, siendo la primera vuelta mucho más competitiva (3.56 puntos porcentuales) que la segunda (5.95 puntos porcentuales); del mismo modo que en Brasil, donde la diferencia en la segunda vuelta entre Dilma Roussef (PT) y Aécio Neves (PSDB) fue también estrecha y competitiva (3.26 puntos porcentuales).

En un segundo grupo, el margen de victoria entre las dos candidaturas más 
Esta obra forma parte del acervo de la Biblioteca Jurídica Virtual del Instituto de Investigaciones Jurídicas de la UNAM www.juridicas.unam.mx

votadas estuvo en torno a los ocho puntos porcentuales (Panamá, Honduras y Paraguay) y en al menos tres casos, los márgenes de victoria no dieron cuenta de escenarios competitivos, como ocurrió en Ecuador (con 34.49 puntos porcentuales de diferencia entre los dos candidatos más votados en la única vuelta que se celebró), en Bolivia (con 36.55 puntos porcentuales de diferencia en beneficio del partido en el gobierno) $y$, en menor medida, en Chile (donde en ambas vueltas las diferencias fueron mayores a los 20 puntos porcentuales) (Tabla Núm. 4).

Tabla Núm. 4

Margen de victoria y nivel de competitividad en las elecciones

presidenciales (2013-2014)

\begin{tabular}{|c|c|c|}
\hline \multirow[t]{2}{*}{ País/año } & \multicolumn{2}{|c|}{$\begin{array}{l}\text { Margen } \\
\begin{array}{l}\text { entre les dos principales } \\
\text { presidenciales }\end{array}\end{array}$} \\
\hline & Primera vuelta & Segunda vuelta \\
\hline Venezuela 2013 & \multicolumn{2}{|l|}{$\begin{array}{l}1.49 \\
\text { (224.268 votos) }\end{array}$} \\
\hline Costa Rica 2014 & $\begin{array}{l}1.36 \\
\text { (25.045 votos) }\end{array}$ & $\begin{array}{l}55.60 \\
\text { (955.721 votos) }\end{array}$ \\
\hline El Salvador 2014 & $\begin{array}{l}9.97 \\
\text { (268.176 votos) }\end{array}$ & $\begin{array}{l}0.22 \\
\text { (6.364 votos) }\end{array}$ \\
\hline Colombia 2014 & $\begin{array}{l}3.56 \\
\text { (458.156 votos) }\end{array}$ & $\begin{array}{l}5.95 \\
\text { (911.985 votos) }\end{array}$ \\
\hline Panamá 2014 & \multicolumn{2}{|l|}{$\begin{array}{l}7.7 \\
(142.934 \text { votos })\end{array}$} \\
\hline Chile 2013 & $\begin{array}{l}21.67 \\
(1.427 .358 \text { votos })\end{array}$ & $\begin{array}{l}24.34 \\
(1.358 .225 \text { votos })\end{array}$ \\
\hline Honduras 2013 & $\begin{array}{l}8.11 \\
\text { (252.804 votos) }\end{array}$ & \\
\hline Paraguay 2013 & $\begin{array}{l}8.72 \\
\text { (213.718 votos) }\end{array}$ & \\
\hline
\end{tabular}


Esta obra forma parte del acervo de la Biblioteca Jurídica Virtual del Instituto de Investigaciones Jurídicas de la UNAM www.juridicas.unam.mx

Dol: http://dx_doi.org/10.22201/iij_.24487910e_2015.7.10092

\begin{tabular}{|l|l|l|}
\hline Ecuador 2013 & $\begin{array}{l}34.49 \\
(2.967 .380 \text { votos })\end{array}$ & No aplica \\
\hline Uruguay 2014 & $\begin{array}{l}16.93 \\
(401.586 \text { votos })\end{array}$ & $\begin{array}{l}13.24 \\
(287.031 \text { votos })\end{array}$ \\
\hline Bolivia 2014 & 36.55 & No aplica \\
\hline Brasil 2014 & $(1.828 .751$ votos $)$ & 3.26 \\
& 8.04 & $(3.459 .963$ votos $)$ \\
\hline
\end{tabular}

Fuente: elaboración propia a partir de resultados electorales oficiales.

Resultados tan estrechos y procesos con alto nivel de incertidumbre generaron tensiones en los comportamientos de los actores que participan en los procesos electorales (El Salvador, Colombia o Venezuela). Estos escenarios competitivos suelen poner en jaque a los organismos electorales - como ocurrió en México en 2006que son mirados con más detenimiento porque al ser tan estrechos los resultados, cada voto cuenta de manera más significativa. No obstante, las reglas y los actores del juego electoral han resuelto los conflictos que se generaron de manera pacífica; los actores políticos, en general, han demostrado madurez frente a los potenciales conflictos al respetar los resultados que anunciaron las autoridades electorales; $;{ }^{19}$ las denuncias de fraude sistemático han sido casi inexistentes y las dificultades se han resuelto a través de los mecanismos legales y los procedimientos existentes. ${ }^{20}$

A diferencia del ciclo electoral 2005-2006, donde las elecciones arrojaron el triunfo en las urnas de los "rebeldes cívicos", ${ }^{21}$ un sector de la ciudadanía que dudaba de la eficacia del voto, rechazaba la participación convencional y prefería los movimientos

\footnotetext{
19 La excepción fue en El Salvador donde al final de la jornada electoral, el partido perdedor se resistió a reconocer los resultados, alegando irregularidades que finalmente no fueron comprobadas. El presidente de Alianza Republicana Nacionalista (ARENA), Jorge Velado, presentó diversos recursos legales para solicitar el recuento de los votos, denunciando anomalías y sospechas de fraude. Véase Periódico El País, "La derecha pide la anulación de las elecciones presidenciales de El Salvador", publicado el 12 de marzo de 2014, http://internacional.elpais.com/internacional/2014/03/12/actualidad/1394594542_283726.htm/

${ }^{20}$ Véanse los informes MOE-OEA.

${ }^{21}$ Freidenberg, Flavia, Los sistemas de partidos..., cit.
} 
Esta obra forma parte del acervo de la Biblioteca Jurídica Virtual del Instituto de Investigaciones Jurídicas de la UNAM www.juridicas.unam.mx

DOI: http://dx.doi.org/10.22201/iij_.24487910e_2015.7.10092

de protesta en la calle, como agentes de cambio; la característica en este maratón electoral ha sido el enfrentamiento y la polarización en torno a cuestiones temáticas como la paz en Colombia, la vieja y la nueva política en Costa Rica o el conflicto ideológico en Venezuela, Brasil o El Salvador.

Precisamente, este maratón ha admitido la legitimación en las urnas de la gestión de algunos de los "rebeldes cívicos". El triunfo de Rafael Correa en Ecuador supone el éxito de la revolución ciudadana; la ratificación de Nicolás Maduro en Venezuela significa la confirmación de su figura como sucesor de Chávez y, la de Morales presume la aceptación de sus reformas sociales y una nueva manera de gestionar la economía y la relación del gobierno con la sociedad. En Bolivia, Ecuador y Venezuela las elecciones implican la inclusión política de sectores que no se sentían representados por las élites políticas tradicionales y que ahora se sienten incluidos bajo un nuevo discurso político que los integra. ${ }^{22}$

\section{Altos niveles de participación de la ciudadanía}

La evaluación de la participación convencional a nivel presidencial para los doce países de la región da cuenta de que los ciudadanos latinoamericanos continúan participando activamente en las elecciones, con niveles que superan la media de 69.90\% (Tabla Núm. 5). Si se comparan los datos del ciclo electoral (2013-2014) con la de los ciclos previos, se encuentra que la participación ciudadana alcanzó niveles casi similares a los de periodos anteriores cuando en promedio general intervino el $70.18 \%$ entre $1978-2006 .^{23}$

La ciudadanía participó activamente en los procesos presidenciales de Bolivia (94.21\%), Uruguay (90.51\%), Ecuador (81.08\%), Brasil (80.61\%), Venezuela (79.69\%) y Panamá (70.00\%), todos ellos por encima de la media regional. A diferencia de ello, los niveles de participación fueron por debajo de la media regional en Costa Rica, Honduras, El Salvador, Colombia. ${ }^{24}$

En dos casos, la participación se incrementó de manera significativa entre la

22 Freidenberg, Flavia y Suárez-Cao, Julieta (eds.), Territorio y poder: nuevos actores y competencia política en los sistemas de partidos multinivel en América Latina, Salamanca, Ediciones Universidad de Salamanca, 2014.

23 Zovatto, Daniel, op. cit.

24 En el caso de Chile, los datos de participación no pueden compararse con elecciones anteriores porque este fue el primer proceso electoral que se realizó tras la reforma en donde se incorporó la inscripción automática y el voto voluntario. 
Esta obra forma parte del acervo de la Biblioteca Jurídica Virtual del Instituto de Investigaciones Jurídicas de la UNAM www.juridicas.unam.mx

Dol: http://dx_doi.org/10.22201/iij.24487910e_2015.7.10092

primera y la segunda vuelta (Colombia y El Salvador), en contextos de alta incertidumbre y polarización entre opciones ideológicas antagónicas. En Colombia, se incrementó al menos en siete puntos porcentuales en la segunda vuelta electoral (40.07\% a 47.89\%). En la segunda vuelta se activó el discurso de la paz —combinado con los programas sociales- y los colombianos se movilizaron en defensa del proyecto del presidente en ejercicio Juan Manuel Santos, quien buscaba reelegirse con un discurso pro-paz. Datos similares se dieron en El Salvador, donde en la primera vuelta sólo acudió a las urnas el 55.30\% del electorado, incrementándose cerca de cinco puntos porcentuales el nivel de participación en la segunda vuelta electoral (60.88\%).

A diferencia de ello, en Costa Rica y Chile, donde también habían dos opciones ideológicas antagónicas, la participación fue menor en la segunda vuelta que en la primera. En Costa Rica, la participación bajó en 11.27 puntos porcentuales entre ambas vueltas, mientras que en Chile la diferencia fue de 7.38 puntos. Esto significa que no es posible asociar, a partir de estos datos preliminares, los niveles de participación con los de polarización ideológica.

Tabla Núm. 5

Participación electoral en elecciones presidenciales

(última elección en cada país)

\begin{tabular}{|c|c|c|c|}
\hline \multirow[t]{2}{*}{ País } & \multicolumn{3}{|c|}{ Participación ciudadana } \\
\hline & $\begin{array}{l}\text { Primera vuelta } \\
\%\end{array}$ & $\begin{array}{l}\text { Segunda vuelta } \\
\%\end{array}$ & Diferencia \\
\hline Bolivia 2014 & 94.21 & No aplica & \\
\hline Uruguay 2014 & 90.51 & 88.57 & -1.94 \\
\hline Ecuador 2013 & 81.08 & No hubo & \\
\hline Brasil 2014 & 80.61 & $s / d$ & \\
\hline Venezuela 2013 & 79.69 & No aplica & \\
\hline Panamá 2014 & 70.00 & No aplica & \\
\hline Paraguay 2013 & 68.60 & No aplica & \\
\hline Costa Rica 2013 & 68.27 & 57.00 & -11.27 \\
\hline Honduras 2013 & 61.16 & No aplica & \\
\hline El Salvador & 55.32 & 60.88 & +5.56 \\
\hline
\end{tabular}


Esta obra forma parte del acervo de la Biblioteca Jurídica Virtual del Instituto de Investigaciones Jurídicas de la UNAM www.juridicas.unam.mx

Dol: http://dx_doi.org/10.22201/iij.24487910e_2015.7.10092

\begin{tabular}{|l|l|l|l|}
\hline 2014 & & & \\
\hline Chile* 2013 & 49.36 & 41.98 & -7.38 \\
\hline Colombia 2014 & 40.07 & 47.89 & +7.82 \\
\hline \multicolumn{2}{|l|}{ Promedio América Latina (primera o única vuelta) } & 69.90 \\
\hline
\end{tabular}

Fuente: elaboración propia a partir de datos oficiales.

*En Chile estas fueron las primeras elecciones tras la reforma electoral que estableció la inscripción automática de los votantes y el voto voluntario, Ley Núm. 20568 de 2011.

\section{Los incumbents (casi) siempre ganan}

Los resultados de las elecciones 2013-2014 estuvieron en consonancia con una de las tendencias más poderosas en América Latina, "Los incumbents (casi) siempre ganan". ${ }^{25}$ Desde mediados de la década de 1980, se han celebrado 23 elecciones en las que el presidente en ejercicio busca la reelección. En todas, salvo dos elecciones, el candidato en el gobierno (incumbent) triunfó en la búsqueda de su reelección. ${ }^{26}$ Los únicos casos de la derrota de un candidato-presidente ocurrieron con Daniel Ortega en Nicaragua (1990) e Hipólito Mejía en la República Dominicana (2004). Ambos son casos de contextos adversos excepcionales. ${ }^{27}$ Todo esto significa que en América Latina hay una ventaja innata al incumbenty que, salvo cuando hay crisis económica, el candidato/a presidente debería ganar la elección. ${ }^{28}$

Desde la década de 1990, la tendencia ha sido establecer la reelección, ya sea

25 Corrales, Javier, "Lo que sorprende y no sorprende de la reelección de Santos", Blog ConDistintosAcentos.com, publicado el 19 de junio, consultado el 3 de agosto de 2014, http://www.condistintosacentos.com/lo-que-sorprende-y-no-sorprende-de-la-re-eleccion-de-santos/

${ }^{26}$ Nicaragua $(1984,1990,2011)$, Perú $(1995,2000)$, Colombia $(2006,2014)$, Argentina $(1995,2011)$, Bolivia (2009, 2014), Ecuador (2009, 2013), Venezuela (2000, 2006), Brasil (1998, 2006, 2014) y República Dominicana $(1990,1994,2004,2012)$.

27 En el primer caso, Ortega pierde porque Nicaragua sobrellevaba una economía desastrosa (hiperinflación de cuatro dígitos). Mejía es derrotado porque la economía estaba en picada y surgió el liderazgo del expresidente Leonel Fernández.

28 En América Latina, el ser incumbent aumenta en un 62\% la probabilidad de ganar una elección. No sólo eso sino que también los incumbents suelen ganar con una ventaja en puntos porcentuales mucho mayor que la que obtienen los ganadores promedios cuando no hay incumbents en la boleta electoral (Penfold et al., en prensa). 
Esta obra forma parte del acervo de la Biblioteca Jurídica Virtual del Instituto de Investigaciones Jurídicas de la UNAM www.juridicas.unam.mx

DOI: http://dx_doi.org/10.22201/iij_.24487910e_2015.7.10092

consecutiva, indefinida o alterna. ${ }^{29}$ En cuatro de los casos analizados ganó el candidato desafiante (Costa Rica, Paraguay, Chile y Panamá), mientras que en cinco se dio la reelección del presidente-candidato (Colombia, Brasil, Bolivia, Venezuela y Ecuador), y en otros tres se reeligió el partido que estaba en ejercicio del Poder Ejecutivo pero con otro candidato (El Salvador, Honduras y Uruguay).

Tabla Núm. 7

Los incumbents, el partido en el poder y los partidos desafiantes en el Poder Ejecutivo

\begin{tabular}{|c|c|c|c|c|c|c|}
\hline & $\begin{array}{l}\text { ¿1ra } \\
2 d a ?\end{array}$ & $\begin{array}{l}\text { ganador } \\
\%\end{array}$ & $\begin{array}{l}\text { Segundo } \\
\%\end{array}$ & $\begin{array}{l}\text { MV } \\
\text { 1ra vuelta }\end{array}$ & $\begin{array}{l}\text { MV } \\
2^{\circ} d a \\
\text { vuelta }\end{array}$ & Ganador/a \\
\hline $\begin{array}{l}\text { Venezuela } \\
2013\end{array}$ & $1 \mathrm{ra}$ & 50.61 & 49,12 & 1.49 & & Incumbent \\
\hline $\begin{array}{l}\text { Costa Rica } \\
2014\end{array}$ & $2 d a$ & 77.22 & 22,1 & & 55.6 & $\begin{array}{l}\text { Partido } \\
\text { Desafiante }\end{array}$ \\
\hline $\begin{array}{l}\text { El Salvador } \\
2014\end{array}$ & $2 d a$ & 50.11 & 49.89 & & 0.22 & $\begin{array}{l}\text { Partido } \\
\text { Incumbent }\end{array}$ \\
\hline $\begin{array}{l}\text { Colombia } \\
2014\end{array}$ & $2 d a$ & 50.95 & 45.00 & & 5.95 & Incumbent \\
\hline Panamá 2014 & & 39.1 & 31.4 & 7.7 & & $\begin{array}{l}\text { Partido } \\
\text { Desafiante }\end{array}$ \\
\hline $\begin{array}{l}\text { Honduras } \\
2013\end{array}$ & & 36.89 & 28.78 & 8.11 & & $\begin{array}{l}\text { Partido } \\
\text { Incumbent }\end{array}$ \\
\hline Paraguay 2013 & - & 45.83 & 37.11 & 8.72 & & $\begin{array}{l}\text { Partido } \\
\text { Desafiante }\end{array}$ \\
\hline Ecuador 2013 & $1 \mathrm{ra}$ & 57.17 & 22.68 & 34.49 & & Incumbent \\
\hline
\end{tabular}

29 Freidenberg, Flavia y Došek, Tomás, “Las reformas electorales..., cit. 
Esta obra forma parte del acervo de la Biblioteca Jurídica Virtual del Instituto de Investigaciones Jurídicas de la UNAM www.juridicas.unam.mx

DOl: http://dx.doi.org/10.22201/ijj.24487910e_.2015.7.10092

\begin{tabular}{|l|l|l|l|l|l|l|}
\hline Chile 2013 & $2 \mathrm{da}$ & 62.17 & 37.87 & & 24.34 & Partido \\
\hline Brasil 2014 & $2 \mathrm{da}$ & 51.63 & 48.37 & 8.04 & 3.26 & Incumbent \\
\hline Bolivia 2014 & $1 \mathrm{ra}$ & 61.04 & 24.49 & 36.55 & & Incumbent \\
\hline Uruguay 2014 & $2 \mathrm{da}$ & 56.62 & 43.38 & 16.93 & 13.24 & Partido \\
\hline
\end{tabular}

Fuente: elaboración propia a partir de datos electorales oficiales.

En cinco países se reeligió al incumbent. En Colombia, tras perder en la primera vuelta, finalmente el presidente Santos consiguió ganar la reelección presidencial consecutiva en un escenario altamente polarizado. Lo mismo ocurrió en Ecuador donde Correa consiguió la reelección consecutiva para avalar la continuidad de su proyecto de Revolución ciudadana, en un escenario poco competitivo y con una mayoría amplia. En Venezuela, Maduro respondió con su triunfo el proyecto de Revolución chavista, aunque lo hizo en un contexto de alta polarización y gran competitividad en la contienda contra la oposición de la Mesa de Unidad bajo el liderazgo de Henrique Capriles, tras el fallecimiento de Hugo Chávez. En Bolivia y Brasil también se reeligió el/la presidente que estaba en el poder.

Otros partidos gobernantes también retuvieron el Ejecutivo, aunque con candidatos diferentes. En El Salvador, el FMLN mantuvo la Presidencia con otro militante propio: el exguerrillero Sánchez Cerén. En Honduras, el Partido Nacional retuvo el control del Ejecutivo. En Uruguay, Tabaré Vázquez consiguió la reelección no inmediata, ya que había sido presidente del país entre 2005 y 2010, y en Chile, Michelle Bachelet regresó a la Moneda junto a la Concertación de Partidos por la Democracia, ahora aliada en Nueva Mayoría, tras su primer mandato entre 20062010.

\section{La fragmentación de los sistemas de partidos: entre el histórico}

\section{multipartidismo y los nuevos sistemas predominantes}

En las últimas décadas, en América Latina, la tendencia se ha encaminado hacia la fragmentación de los sistemas de partidos, generando dinámicas cada vez más multipartidistas. ${ }^{30}$ Los datos evidencian que en la primera elección post-transición el

\footnotetext{
${ }^{30}$ Freidenberg, Flavia, Los sistemas de partidos..., cit.
} 
Esta obra forma parte del acervo de la Biblioteca Jurídica Virtual del Instituto de Investigaciones Jurídicas de la UNAM www.juridicas.unam.mx

DOI: http://dx.doi.org/10.22201/iij_.24487910e_2015.7.10092

número efectivo de partidos (NEP) medio era de 2.82 y que, en la actualidad, calculando sobre cada una de las últimas elecciones legislativas celebradas en la región, ese número ha ascendido a 3.89 (Tabla Núm. 6). ${ }^{31}$

Esta mayor fragmentación electoral podría pensarse en diferentes términos: a) como la representación natural de diversas tendencias ideológicas e intereses sociales; b) como la incorporación de nuevos actores en la política institucionalizada, y c) como el resultado del uso de los partidos como vehículos personales de líderes caudillistas o de coaliciones electorales volátiles que crean partidos como una manera de resolver su descontento por los resultados generados por conflictos internos.

A pesar de esa tendencia multipartidista, los datos comparados muestran que algunos países han mantenido durante todo el periodo una estructura bipartidista del sistema, con dos claras opciones que actúan en la lógica de gobierno-oposición (Nicaragua, República Dominicana, El Salvador y Paraguay). México, Honduras, Panamá o Costa Rica también cuentan con baja fragmentación pero el nivel de dispersión de los apoyos ha ido modificándose de manera gradual en las últimas décadas.

En dos casos, como Bolivia y Ecuador, la dinámica multipartidista ha experimentado cambios sustanciales, reduciéndose la fragmentación de manera significativa. ${ }^{32}$ En Bolivia, tras el colapso de los partidos tradicionales como el MNR, se ha renovado gran parte de las élites gobernantes y se ha producido el cambio desde un sistema multipartidista extremo a otro de partido predominante. En este nuevo

\footnotetext{
31 La fórmula para calcular el índice de fraccionalización o fragmentación a partir de la propuesta de Rae (1971) es la siguiente:
}

$$
\mathrm{F}=1-\left(\Sigma \mathrm{Ti}^{2}\right)
$$

donde $\mathrm{Ti}=$ es el porcentaje de votos (o de escaños) de cada partido. Este índice permite apreciar la relación existente entre el número de partidos y su tamaño, se aplica tanto al campo electoral (votos) como al legislativo (escaños) y abarca teóricamente desde cero, que sería la situación hipotética de que todos los votantes se inclinaran por el mismo partido o que todos los legisladores pertenecieran al mismo partido, lo que supone una ausencia de competencia, y uno, que es la situación hipotética de que todos los votantes se inclinaran por distintos partidos o que todos los parlamentarios pertenecieran a partidos diferentes y que, por tanto, hubiera tantas opciones partidistas como casos en competencia. A partir de esa fórmula de fragmentación se puede calcular del siguiente modo $\mathrm{N}=1 /(1-\mathrm{F})$.

${ }^{32}$ En estos dos países andinos se dio una reducción de cerca de dos puntos de NEP legislativo entre la primera y la última elección. En Bolivia, fue de 4.31 en 1985, a 1.91 en 2014 y en Ecuador fue de 2.83 en 1979 a, 1.83 en 2013. 
Esta obra forma parte del acervo de la Biblioteca Jurídica Virtual del Instituto de Investigaciones Jurídicas de la UNAM www.juridicas.unam.mx

escenario, el MAS adquirió una posición relevante ya que reunió más de la mitad de los sufragios, con porcentajes que parecían hasta ese momento fuera del alcance de cualquier organización política, en particular gracias a su implantación rural en las tierras altas.

Tabla Núm. 6

Número efectivo de partidos en las elecciones legislativas de América Latina (1978-2014)

\begin{tabular}{|l|l|l|l|l|l|}
\hline País & Elecciones legislativas & $\begin{array}{l}\text { NEP } \\
\text { Inicial }\end{array}$ & $\begin{array}{l}\text { NEP } \\
\text { Última elec } \\
\text { ción }\end{array}$ & $\begin{array}{l}\text { Magnitud } \\
\text { cambio }\end{array}$ & Media \\
\hline $\begin{array}{l}\text { Nicara- } \\
\text { gua }\end{array}$ & $84,90,96,01,06,11$ & 2.28 & 1.80 & -0.48 & 2.33 \\
\hline $\begin{array}{l}\text { Hondura } \\
\text { S }\end{array}$ & $81,85,89,93,97,01,05,09,13$ & 2.17 & 3.51 & 1.34 & 2.36 \\
\hline $\begin{array}{l}\text { Domini- } \\
\text { cana }\end{array}$ & $\begin{array}{l}78,82,86,90,94,98,02,06,08 \\
10\end{array}$ & 1.99 & 2.01 & 0.02 & 2.43 \\
\hline $\begin{array}{l}\text { Para- } \\
\text { guay }\end{array}$ & $89,93,98,03,08,13$ & 1.89 & 2.39 & 0.5 & 2.59 \\
\hline $\begin{array}{l}\text { México } \\
85,88,91,94,97,00,03,06,09 \\
11\end{array}$ & 1.83 & 3.68 & 1.85 & 2.82 \\
\hline $\begin{array}{l}\text { Panamá } \\
94,99,04,09,14\end{array}$ & 4.33 & 3.01 & -1.32 & 2.86 \\
\hline $\begin{array}{l}\text { Uruguay } \\
\text { zuela }\end{array}$ & $78,89,94,99,04,09,14$ & 2.92 & 2.65 & -0.27 & 2.90 \\
\hline $\begin{array}{l}\text { Costa } \\
\text { Rica }\end{array}$ & $\begin{array}{l}78,82,86,90,94,98,02,06,10 \\
14\end{array}$ & 2.38 & 4.87 & 1.52 & 2.97 \\
\hline $94,97,00,03,06,09,12$ & 3.06 & 3.19 & 0.13 & 3.14 \\
\hline El & 2.65 & 2.65 & 0 & 3.21 \\
\hline
\end{tabular}


Esta obra forma parte del acervo de la Biblioteca Jurídica Virtual del Instituto de Investigaciones Jurídicas de la UNAM www.juridicas.unam.mx

DOI: http://dx_doi.org/10.22201/iij_.24487910e_2015.7.10092

\begin{tabular}{|l|l|l|l|l|l|}
\hline $\begin{array}{l}\text { Argenti- } \\
\text { na }\end{array}$ & $\begin{array}{l}83,85,87,89,91,93,95,97,99 \\
01,05,07,09,11,13\end{array}$ & 2.19 & 3.10 & 0.91 & 3.32 \\
\hline Perú & $80,85,90,95,00,01,06,11$ & 2.46 & 3.97 & 1.51 & 3.48 \\
\hline Bolivia & $85,89,93,97,02,05,09,14$ & 4.31 & 1.91 & -2.4 & 3.54 \\
\hline $\begin{array}{l}\text { Guate- } \\
\text { mala }\end{array}$ & $99,03,07,11$ & 2.35 & 4.70 & 2.35 & 3.75 \\
\hline $\begin{array}{l}\text { Colom- } \\
\text { bia }\end{array}$ & $82,86,90,91,94,98,02,06,10$ & 1.98 & 4.98 & 3.00 & 3.80 \\
\hline Chile & $89,93,97,01,05,09,13$ & 5.07 & 6.50 & 1.43 & 5.42 \\
\hline Ecuador & $\begin{array}{l}79,84,86,88,90,92,94,96,98 \\
02,06,09,13\end{array}$ & 4.03 & 1.83 & -2.20 & 5.79 \\
\hline Brasil & $86,90,94,98,02,06,10,14$ & 2.83 & 13.22 & 10.39 & 8.55 \\
\hline Media regional & 2.82 & 3.89 & 3.63 \\
\hline
\end{tabular}

El número efectivo de partidos se ha calculado sobre la base del número de escaños, empleando la fórmula de Laakso y Taagapera (1979).

Fuente: elaboración propia a partir de la Base de datos de elecciones en América Latina, Salamanca, Instituto de Iberoamérica, Universidad de Salamanca, 1978-2014.

\section{Gobiernos divididos vs. presidentes fuertes}

con mayorías legislativas

El hecho de que un presidente no cuente con mayoría en el Legislativo genera gobiernos de minoría (también denominados "gobiernos divididos"). El tipo de relaciones de cooperación o confrontación que se den entre el Ejecutivo y el Legislativo pueden ser claves para la gobernabilidad democrática. En este sentido, presidentes minoritarios sin un bloque legislativo que le apoye, tendrán más dificultades para conseguir una mayoría que les respalde y, por tanto, habrá menos condiciones para generar gobernabilidad.

De las doce elecciones, en tres se generaron gobiernos divididos, donde el presidente no cuenta con mayoría de su partido en el Legislativo (Costa Rica, El 
Esta obra forma parte del acervo de la Biblioteca Jurídica Virtual del Instituto de Investigaciones Jurídicas de la UNAM www.juridicas.unam.mx

Salvador y Panamá). En el resto, se dieron gobiernos unitarios con presidentes fuertes, que contaban con respaldo de su partido y/o coalición de gobierno desde el Legislativo (Colombia, Honduras, Ecuador, Venezuela, Brasil, Uruguay, Paraguay, Chile) (Tabla Núm. 8).

Tabla Núm. 8

Gobierno dividido y mayorías legis/ativas en América Latina

\begin{tabular}{|c|c|c|c|c|}
\hline \multirow[t]{2}{*}{ País } & \multirow{2}{*}{$\begin{array}{l}\text { Resolución } \\
\text { presidencial } \\
\text { (c/balotage) }\end{array}$} & \multicolumn{3}{|l|}{ Partido de gobierno } \\
\hline & & Partido en el Ejecutivo & $\begin{array}{l}\text { Mayoría en el } \\
\text { Congreso }\end{array}$ & $\begin{array}{l}\text { Gobierno } \\
\text { dividido }\end{array}$ \\
\hline Honduras & - & PNH & Si (propia) & No \\
\hline Chile & $\begin{array}{l}\text { Segunda } \\
\text { vuelta }\end{array}$ & Concertación & Si (propia) & No \\
\hline Costa Rica & $\begin{array}{l}\text { Segunda } \\
\text { vuelta }\end{array}$ & PAC & No (PLN) & Si \\
\hline Colombia & $\begin{array}{l}\text { Segunda } \\
\text { vuelta }\end{array}$ & $\begin{array}{l}\text { Partido Social de la } \\
\text { Unidad (PU) }\end{array}$ & Si (propia) & No \\
\hline Ecuador & $\begin{array}{l}\text { Primera } \\
\text { vuelta }\end{array}$ & Alianza PAÍS & SI (propia) & No \\
\hline El Salvador & $\begin{array}{l}\text { Segunda } \\
\text { vuelta }\end{array}$ & FMLN & No (ARENA) & Si \\
\hline Panamá & - & $\begin{array}{l}\text { PAN + PP } \\
\text { (El pueblo primero) }\end{array}$ & $\begin{array}{l}\text { NO (Unidos por } \\
\text { más cambios) }\end{array}$ & $\mathrm{Si}$ \\
\hline Paraguay & - & ANR-Colorado & Si (propia) & No \\
\hline Venezuela & $\begin{array}{l}\text { Segunda } \\
\text { vuelta }\end{array}$ & PSUV & Si (propia) & No \\
\hline Uruguay & $\begin{array}{l}\text { Segunda } \\
\text { vuelta }\end{array}$ & Frente Amplio & Si (propia) & No \\
\hline Bolivia & $\begin{array}{l}\text { Primera } \\
\text { vuelta }\end{array}$ & MAS & Si (propia) & No \\
\hline
\end{tabular}


Esta obra forma parte del acervo de la Biblioteca Jurídica Virtual del Instituto de Investigaciones Jurídicas de la UNAM www.juridicas.unam.mx

DOI: http://dx.doi.org/10.22201/iij.24487910e_2015.7.10092

\begin{tabular}{|l|l|l|l|l|}
\hline Brasil & $\begin{array}{l}\text { Segunda } \\
\text { vuelta }\end{array}$ & PT & Si (propia) & No \\
\hline
\end{tabular}

Fuente: elaboración propia a partir de resultados oficiales.

* Partido de gobierno con bloque mayoritario en el Legislativo.

\section{Campañas negativas con alta polarización ideológica}

Otro elemento que ha destacado ha sido la proliferación de campañas negativas en el marco de la profunda polarización ideológica de las sociedades latinoamericanas. Estas estrategias han estado enmarcadas con la ideología de que las campañas electorales fomentaron el odio entre los candidatos. En el caso de la reelección colombiana, la venezolana, la brasileña o la salvadoreña, los estrategas buscaron polarizar, a través de los contenidos de los discursos y las propias campañas, las posiciones de los contendientes y sus partidos.

Los seguidores de Santos movilizaron en torno a la búsqueda de la paz y como un apoyo expreso y directo al proceso de negociación que se está llevando a cabo en Cuba, empleando la figura del expresidente Uribe y el recuerdo de la política de seguridad ciudadana, mientras que los partidarios de Zuluaga lo hicieron en contra este proceso. Algo similar ocurrió en El Salvador, donde nuevamente el conflicto de la guerra civil se revivió y enfrentó a los dos partidos tradicionales mayoritarios frente a temas de seguridad, política de "mano dura" y la economía. ${ }^{33}$ En Venezuela, el enfrentamiento entre los chavistas y la oposición dio cuenta de esa creciente polarización ideológica. En Brasil, la división entre los petistas y los otros ha generado un profundo enfrentamiento entre dos modelos de país.

\section{Las organizaciones de partidos importan}

A diferencia de lo que suele señalarse respecto a la política latinoamericana, las elecciones han dado muestra de la importancia de algunas organizaciones de partidos en un clima de crisis de representación y erosión de las etiquetas partidistas

\footnotetext{
${ }^{33}$ Véase el análisis sobre las recientes elecciones salvadoreñas y el nivel de polarización entre las dos candidaturas principales. Gabriel Martínez y Alfonso Myers, “Polarización ideológica y políticas públicas en materia de seguridad y economía: las elecciones presidenciales de El Salvador", publicado en el Blog ConDistintosAcentos.com, 5 de febrero de 2014, consultado el 6 de enero de 2015, http://Www.condistintosacentos.com/polarizacion-ideologica-y-politicas-publicas-en-materia-deseguridad-y-economia-las-elecciones-presidenciales-en-el-salvador-2014/
} 
Esta obra forma parte del acervo de la Biblioteca Jurídica Virtual del Instituto de Investigaciones Jurídicas de la UNAM www.juridicas.unam.mx

DOl: http://dx.doi.org/10.22201/iij.24487910e_2015.7.10092

tradicionales. ${ }^{34}$ El PAN en Panamá, el PAC en Costa Rica, la Concertación de Partidos por la Democracia en Chile, el ANR-Partido Colorado en Paraguay, el PT en Brasil, el PNH en Honduras, el Frente Amplio en Uruguay o el FMLN en El Salvador han mostrado su capacidad como organizaciones para movilizar seguidores, disputar el centro político y ganar elecciones en diferentes niveles institucionales.

Rousseff, Vázquez, Varela, Bachelet, Hernández, Solíz o Sánchez Cerén son militantes con trayectoria política dentro de sus organizaciones. En un contexto en el que están triunfando nuevos partidos que promueven una nueva manera de hacer política (como viene pregonando el PAC costarricense desde hace algunos años) y como expresión de la superación de la crisis de representación, el electorado ha preferido a los candidatos de partidos tradicionales y han dado cuenta de la relevancia de esos partidos en la movilización y representación electoral.

\section{EL MARATÓN ELECTORAL EN PERSPECTIVA COMPARADA: LO QUE HEMOS APRENDIDO Y LO QUE AÚN QUEDA POR APRENDER}

El maratón electoral de 2013-2014 estuvo monopolizado por doce elecciones presidenciales, ocho elecciones legislativas y varias subnacionales. Las tendencias muestran que las elecciones han cumplido con su función principal la renovación de las autoridades y la de generar oportunidades para que la ciudadanía exprese, en libertad y de manera pacífica, sus preferencias. Las elecciones de este maratón, sobre todo las presidenciales, han mostrado escenarios hipercompetitivos, muy polarizados, y con alto nivel de incertidumbre. También han dado cuenta del papel de las organizaciones de partidos frente a la personalización de la política (a pesar de ciertos líderes carismáticos u outsiders), incluso mostrando la capacidad de estas organizaciones de partidos para adaptarse a nuevos escenarios, movilizarse en el terreno y generar una campaña paralela en las redes sociales.

El nuevo ciclo electoral también ha dejado algunos desafíos. Primero, el de ser capaces de representar con gobiernos divididos, donde los presidentes no cuentan con mayorías que les respalden en los Congresos (Panamá, El Salvador o Costa Rica). Segundo, el de proveer gobernabilidad democrática, siendo eficientes en la satisfacción de las demandas ciudadanas, en contextos fragmentados electoralmente y con altos niveles de polarización. Tercero, el de incluir a grupos sociales y políticos que se sienten poco representados, en un contexto de disolución de los vínculos de

\footnotetext{
34 Lupu, Noam, "Brand Dilution and the Breakdown of Political Parties in Latin America”, World Politics, vol. 66, núm. 4, 2014, pp. 561-602; Freidenberg, Flavia y Suárez-Cao, Julieta, Territorio y poder..., cit.
} 
Esta obra forma parte del acervo de la Biblioteca Jurídica Virtual del Instituto de Investigaciones Jurídicas de la UNAM www.juridicas.unam.mx

DOI: http://dx.doi.org/10.22201/iij_.24487910e_2015.7.10092

los electores con las etiquetas (marcas) partidistas tradicionales. ${ }^{35}$ Cuarto, el de conseguir mecanismos que permitan hacer a los sistemas políticos más flexibles y con capacidad de adaptación cuando las opciones más radicales no puedan dar respuesta desde el gobierno a todas las expectativas sociales y económicas que han generado.

Las crisis económicas y sociales prolongadas (y sus consecuencias con el aumento del desempleo, la pobreza y la desigualdad) y el compromiso de los partidos de centro con los planes de ajuste económico (políticas de ajuste, el achicamiento del Estado, endeudamiento, entre otras) impactaron sobre el sistema político, minando los niveles de confianza de la ciudadanía hacia esos partidos cuando no fueron capaces de responder y adaptarse a las exigencias sociales. ${ }^{36}$

Mientras algunas élites políticas observan aún cuasi-indiferentes los drásticos cambios que se dan en algunos sistemas políticos latinoamericanos (e incluso europeos) en materia de representación política (como en El Salvador, en República Dominicana o en México), sin generar instrumentos que les permitan adaptarse a las nuevas exigencias sociales; en otros sistemas políticos, los partidos de las élites tradicionales pro status quo ya han colapsado (Ecuador, Bolivia o Venezuela) y se enfrentan a importantes desafíos respecto a su supervivencia como actores políticos representativos de las demandas ciudadanas. ${ }^{37}$

La incapacidad de las élites políticas tradicionales pro status quo para adaptarse a los cambios de la sociedad y dar respuestas satisfactorias a los (viejos y nuevos) problemas de la ciudadanía en un escenario de ajuste económico y vaciamiento del centro político parecen tener más peso (que otros factores) para explicar el colapso del sistema de partidos y la emergencia de nuevos actores. ${ }^{38}$ Cuanto mayor fue la crisis social y económica, y mayor el compromiso bipartidista (o de los partidos

\footnotetext{
${ }^{35}$ Lupu, Noam, op. cit.

36 Freidenberg, Flavia y Casullo, María Esperanza, “The Rise of Outsider Politicians in Latin America and Europe", The Monkey Cage, publicado el 16 de septiembre de 2014, http://www.washingtonpost.com/blogs/monkeycage/wp/2014/09/16/the-rise-of-outsider-politicians-in-
} latin-america-and-europe/; Carreras, Miguel, "The Rise of Outsiders in Latin America, 1980-2010: An Institutionalist Perspective", Comparative Political Studies, vol. 45, núm 12, 2012, pp. 1451-1482; Sagarzazu, Iñaki, "Nación vs. región: las tensiones del sistema de partidos venezolano postcolapso", América Latina Hoy, Revista de Ciencias Sociales, vol. 58, 2011, pp. 121-142.

${ }^{37}$ Freidenberg, Flavia y Casullo, María Esperanza, op.cit.

38 Ibidem; Sagarzazu, Iñaki, op.cit. 
Esta obra forma parte del acervo de la Biblioteca Jurídica Virtual del Instituto de Investigaciones Jurídicas de la UNAM www.juridicas.unam.mx

DOI: http://dx_doi.org/10.22201/iij.24487910e_2015.7.10092

mayoritarios) con el ajuste, mayor el derrumbe de los partidos de centro (caso de Venezuela, de Ecuador o de Bolivia).

En estos países, el vaciamiento del centro partidista fue concomitante con la aparición de liderazgos outsiders, ${ }^{39}$ que culminaron en transformaciones de la estructura y de la lógica de la competencia a la que estaban acostumbrados los actores tradicionales del sistema de partidos ${ }^{40}$ llegando en la mayoría de ellos al colapso de los partidos mayoritarios del sistema de partidos previo, por su incapacidad para generar estrategias y dinámicas de adaptación organizativa y/o programática.

En este sentido, las elecciones del último maratón electoral enfrentaron a los actores partidistas a nuevos desafíos respecto a la superación de ese vaciamiento del centro ideológico que se ha dado en las últimas décadas. Entre los desafíos destacan: a) la superación de la "cancha inclinada", donde los candidatos que se encuentran en el ejercicio del gobierno cuentan con recursos que desnivelan la competencia (como en Ecuador, Venezuela o Bolivia); condicionando con ello b) la celebración de elecciones de integridad, y c) la dificultad para que la democracia se extienda a todos los ciudadanos $y$ en todo el territorio, superando los "autoritarismos subnacionales". ${ }^{41}$

El antídoto más eficaz ante la cancha inclinada, los outsiders, el rechazo a la política y el populismo autoritario son las instituciones democráticas, el control político a través de procesos de accountability, el aprendizaje ciudadano de los valores y las prácticas democráticas y el fortalecimiento de los partidos políticos. Por ello, el modo en que los partidos se comportan está estrechamente vinculado a la calidad de las instituciones democráticas. Su éxito en el cumplimiento de algunas tareas como la de representación, gobierno y articulación de intereses supone un avance en la democratización de los sistemas políticos.

Comportamientos extremadamente polarizados, poco cooperativos y confrontacionales hacen que la calidad de la democracia se vea afectada. Es por ello, que resulta fundamental voluntad política, el diálogo, la cooperación y las reglas de juego para mejorar la calidad de un sistema democrático. Aunque se pongan en práctica los diseños institucionales más avanzados, es muy probable que todo quede

\footnotetext{
${ }^{39}$ Carreras, Miguel, op.cit.

40 Freidenberg, Flavia y Suárez-Cao, Julieta, op.cit.

${ }^{41}$ Gervasoni, Carlos, op.cit.
} 
Esta obra forma parte del acervo de la Biblioteca Jurídica Virtual del Instituto de Investigaciones Jurídicas de la UNAM www.juridicas.unam.mx

DOI: http://dx.doi.org/10.22201/iij.24487910e_2015.7.10092

en papel mojado si no hay un compromiso de la ciudadanía y voluntad política de las élites por el respeto al Estado de derecho y al pluralismo político.

\section{FUENTES CONSULTADAS}

CARRERAS, Miguel, "The Rise of Outsiders in Latin America, 1980-2010: An Institutionalist Perspective", Comparative Political Studies, vol. 45, núm 12, 2012.

CORRALES, Javier, "Lo que sorprende y no sorprende de la reelección de Santos", Blog ConDistintosAcentos.com, publicado el 19 de junio, consultado el 3 de agosto de 2014, http://Www.condistintosacentos.com/lo-que-sorprende-y-no-sorprende-dela-re-eleccion-de-santos/

DAHL, Robert, La poliarquía, Madrid, Tecnos, 1971.

FreidenberG, Flavia y DOŠEK, Tomás, "Las reformas electorales y la fortaleza institucional en América Latina", trabajo presentado para su discusión en el II Congreso Internacional de Estudios Electorales, organizado por el Jurado Nacional de Elecciones, Lima, del 27 al 29 de noviembre de 2014.

_- - - "Estabilidad y cambio de los sistemas de partidos de América Latina", en Freidenberg, Flavia (ed.), Los sistemas de partidos de América Latina, 1978-2015, México, Instituto Nacional Electoral, Tribunal Electoral del Poder Judicial de la Federación e Instituto de Iberoamérica, Universidad de Salamanca, 2015 (en prensa).

_-_ y Casullo, María Esperanza, "The Rise of Outsider Politicians in Latin America and Europe", The Monkey Cage, publicado el 16 de septiembre de 2014, http://www.washingtonpost.com/blogs/monkeycage/wp/2014/09/16/the-rise-ofoutsider-politicians-in-latin-america-and-europe/

-_- - Suárez-Cao y Julieta (eds.), Territorio y poder: nuevos actores y competencia política en los sistemas de partidos multinivel en América Latina, Salamanca, Ediciones Universidad de Salamanca, 2014.

GERVASONI, Carlos, “Democracia, autoritarismo e hibridez en las provincias argentinas: la medición y causa de los regímenes subnacionales", Journal of Democracy en español, vol. 3, 2011.

LAAKSO, Markku y TAAGEPERA, Rein, "Effective number of parties. A Measure with Application to West Europe", Comparative Political Studies, vol. 12, núm. 1, 1979.

LEVITSKY, Steven y WAY, Lucas, "Elecciones sin democracia: el surgimiento de los regímenes autoritarios competitivos", Estudios Políticos, Colombia, vol. 24, enero- 
Esta obra forma parte del acervo de la Biblioteca Jurídica Virtual del Instituto de Investigaciones Jurídicas de la UNAM www.juridicas.unam.mx

Dol: http://dx_doi.org/10.22201/iij.24487910e_2015.7.10092

junio, 2004.

LINZ, Juan J, La quiebra de las democracias, Madrid, Alianza Editorial, 1987.

LUPU, Noam, "Brand Dilution and the Breakdown of Political Parties in Latin America", World Politics, vol. 66, núm. 4, 2014.

PÉREZ-LiÑÁN, Aníbal, “Los efectos del ballotage en los sistemas electorales y de partidos en América Latina", trabajo presentado para el Segundo Seminario Iberoamericano sobre Partidos Políticos, Cartagena de Indias, septiembre de 2006.

NoRRIS, Pippa, Why electoral integrity matters, Nueva York, Cambridge University Press, 2014.

PENFOLD, Michael, Corrales, Javier et al., "Los invencibles: la reelección presidencial y los cambios constitucionales en América Latina", Revista de Ciencia Política, 2014.

Polilat, Índice de Desarrollo Democrático de América Latina, Buenos Aires, Konrad Adenauer Stiftung, 2013, http://Www.kas.de/wf/doc/kas_35551-1522-430.pdf?130930145657

RAE, Douglas, The Political Consequences of Electoral Laws, New Haven, Yale University Press, 1971.

SAGARZAZU, Iñaki, “Nación vs. región: las tensiones del sistema de partidos venezolano postcolapso", América Latina Hoy, vol. 58, 2011.

Schattschneider, Elmer E., Party Government, Nueva York, Holt, Rinehart and Winston, 1942.

Zovatto, Daniel, “Elecciones y democracia en América Latina. Balance electoral latinoamericano noviembre 2005-diciembre 2006", presentada en el Seminario de Balance Electoral de América Latina, organizado en el Centro de Estudios Constitucionales, Madrid, 13 de diciembre de 2006.

\section{Bases de Datos}

Base de Datos de "Elecciones en América Latina", Salamanca, Instituto de Iberoamérica, Universidad de Salamanca, 1978-2014.

Proyecto de Investigación "Sistemas de partidos subnacionales y calidad de la democracia en América Latina" (SISPSUB), Salamanca, Instituto de Iberoamérica, Universidad de Salamanca, 1978-2015. 